\title{
Isolated tumour cells and micrometastases in intraductal breast cancer: a simple mechanical question in some cases
}

\author{
A Piñero-Madrona*,1 , J A Ruiz- Maciá ${ }^{2}$, C Zaragoza-Zaragoza ${ }^{3}$, L Polo-García ${ }^{4}$ and J Sola-Pérez ${ }^{4}$ \\ ${ }^{1}$ Department of General Surgery, 'Virgen de la Arrixaca' University Hospital, 30120 Murcia, Spain; ${ }^{2}$ Department of Pathology, \\ Hospital de la Vega Baja, 03314 Orihuela, Spain; ${ }^{3}$ Department of General Surgery, Hospital de la Vega Baja, 03314 Orihuela, Spain \\ and ${ }^{4}$ Department of Pathology 'Virgen de la Arrixaca' University Hospital, 30120 Murcia, Spain
}

Sir,

A recent work remarks the influence of molecular lymph node assay to diagnose micrometastases in the sentinel node of intraductal carcinoma of the breast (Osako et al, 2012). In fact, the detection of small epithelial cell aggregates became much more frequent as the sentinel lymph node biopsy replaced complete axillary dissection as a method of staging breast cancer patients. The implementation of much more sensitive and specific techniques into the clinical analysis of the sentinel node, such as techniques based on molecular biology, has increased the detection of minimum tumour loads. The OSNA technique (one step-nucleic acid-amplification) detects cytokine 19 mRNA expression after processing the node, and therefore, identifies the presence of cells from the breast tumour whenever this protein is expressed by the tumour. This method is so sensitive that it permits the detection of isolated tumour cells, and, consequently, its clinical use has led to an increase in the diagnosis of micrometastasis and submicrometastasis.

At the same time, in the diagnosis of primary breast lesions, both the development of early detection programmes and technological advances in diagnostic image tests, especially mammography, have led to the diagnosis of carcinomas at increasingly earlier stages, thus reducing the probability of dissemination from the primary tumour. Definitive preoperative diagnosis is fundamentally based on the biopsy of the lesion by taking a sample using a core needle biopsy device. The use of this device makes it possible to obtain a sample for both the histological and cytological diagnosis, as well as permitting the use of inmunohistochemical analysis which is currently essential for planning the management of these tumours. By using a core needle biopsy, a diagnosis can be obtained, but a drawback is that we cannot know if this is representative of the whole of the tumour, as it only provides a sample. Therefore, it is usually repeated in different areas of the lesion.
Related to the sentinel node biopsy, the classical concept of intradutal carcinoma contrasts with the following two findings: (a) $\sim 9 \%$ of the cases of all published series involve infiltrated lymph nodes when sentinel node analysis is used as the staging method (Smith, 2010); and (b) in 1-2\% of the cases the patient presents with specific mortality related to breast cancer in the follow-up period in spite of appropriate treatment (Ernster et al, 2000).

The most common explanation to this is that the pathologist's analysis was not thorough enough to detect the microinfiltration foci responsible for these events (Intra et al, 2008), although some other reasons have been suggested for the appearance of these cells in the sentinel node (Banys et al, 2012). For invasive breast cancer, some authors group these phenomena as benign mechanical transport, and two main modes have been proposed: surgeryinduced tumour cell displacement (Osako et al, 2012) and breast massage used to facilitate the intraoperative localisation of sentinel nodes (Diaz et al, 2005).

After reviewing the cases of intraductal carcinoma of the breast that had sentinel node biopsies with OSNA technique in our centres, we have found seven cases of node infiltration in which intraductal carcinoma was diagnosed after an exhaustive search involving the removal of the surgical piece without finding microinfiltration foci, and having ruled out any other breast focus of the carcinoma. The general characteristics of these cases are shown in Table 1, and two interesting facts should be highlighted: first, all of them presented with more than four biopsies, in other words at least four cylinders had been extracted in many other punctures of the lesion, and in one case in which a preoperative diagnosis was established by using fine needle aspiration, many passes were carried out until more than five extensions were obtained for cytological analysis; and second, a low tumour load was diagnosed, in which the number of copies of CK19 mRNA found was no greater than 1200 , that is to say, they were cases of 
Table 1. General characteristics of intraductal carcinoma, preoperative biopsy and tumour load found in the sentinel node

\begin{tabular}{|c|c|c|c|c|c|c|}
\hline Age (years) & $\begin{array}{l}\text { Lesion } \\
\text { size }(\mathrm{mm})\end{array}$ & Grade & Necrosis & $\begin{array}{l}\text { Diagnostic } \\
\text { method }\end{array}$ & $\begin{array}{l}\text { No. of biopsies/ } \\
\text { punctures }\end{array}$ & $\begin{array}{c}\text { No. of copies of } \\
\text { OSNA }\end{array}$ \\
\hline 59 & 10 & High & Yes & CNB & 6 & 1200 \\
\hline 67 & 15 & Intermediate & Yes & CNB & 4 & 1100 \\
\hline 51 & 26 & High & Yes & FNA & 5 & $<250$ \\
\hline 66 & 15 & High & Yes & CNB & 5 & 800 \\
\hline 42 & 30 & Intermediate & No & CNB & 5 & 360 \\
\hline 40 & 35 & High & Yes & CNB & 8 & 360 \\
\hline 49 & 30 & Intermediate & No & CNB & 4 & 360 \\
\hline
\end{tabular}

micrometastasis (three cases with $<400$ copies) and submicrometastasis or isolated tumour cells (one case). These findings support the proposed mechanical theory related to the preoperative core needle biopsy: its performance can lead to the destructuring of the area, the seeding of cells in the trajectory of the needle and even the translocation of these to the lymphovascular area (Bilows, 2010).

According to the findings of other authors, we would like to emphasise that care should be taken because this mechanism could account for the presence of tumour cells in the sentinel node of truly intraductal lesions, above all in those people in whom a significant number of preoperative needle passes have been carried out, and the biological significance of these cells should be equivalent to that of a negative sentinel node.

\section{REFERENCES}

Banys M, Gruber I, Krawczyk N, Becker S, Kurth R, Wallwiener D, Jakubowska J, Hoffman J, Rothmund R, Staebler A, Fehm T (2012) Hematogenous and lymphatic tumour cell dissemination may be detected in patients diagnosed with ductal carcinoma in situ of the breast. Breast Cancer Res Treat 131: 801-808.

Bilows M (2010) Breast core needle biopsy: issues and controversias. Mod Pathol 23: S36-S45.

Diaz NM, Vrcel V, Centeno BA, Muro-Cacho C (2005) Modes of benign mechanical transport of breast epithelial cells to axillary lymph nodes. Adv Anat Pathol 12: 7-9.

Ernster VL, Barclay J, Kerlikowske K, Wilkie H, Ballard-Barbash R (2000) Mortality among women with ductal carcinoma in situ of the breast in the population-based surveillance, epidemiology and end results program. Arch Intern Med 160: 953-958.

Intra M, Rotmensz N, Veronesi P, Colleoni M, Iodice S, Paganelli G, Viale G, Veronesi U (2008) Sentinel node biopsy is not a standard procedure in ductal carcinoma in situ of the breast: the experience of the European Institute of Oncology on 854 patients in 10 years. Ann Surg 247: 315-319.

Osako T, Iwase T, Kimura K, Masumura K, Horii R, Akiyama F (2012) Incidence and possible pathogenesis of sentinel node micrometastases in ductal carcinoma in situ of the breast detected using molecular whole lymph node assay. Br J Cancer 106: 1675-1681.

Smith BL (2010) Clinical applications of breast pathology: management of in situ breast carcinomas and sentinel node biopsy issues. Mod Pathol 23: S33-S35. 